\title{
Sex, Drugs, and Alcohol in the Digital Neighborhood: A multi-method analysis of online discourse amongst Black and Hispanic Youth
}

In the digital neighborhood, Black and Hispanic youth communicate their perspectives about a myriad of issues facing youth, including sex and substance use. This population of young people are also disproportionately burdened by negative outcomes associated with sex and substance use behaviors, even when their behavior is less risky. Given the increased likelihood of negative outcomes, we investigated how youth talk about these behaviors in their online social networks. This mixed methods study integrates a behavioral survey with a machine learning-supported, qualitative content analysis of one year of Facebook and Twitter posts from 50 participants, with feedback from a youth advisory board. Findings suggest that participants who drank were more likely to post about alcohol. Women posted more about STIS, HIV and pregnancy. Posts around sexual behavior often discussed trust in sexual partnerships and gendered views of sex. Alcohol and marijuana were used to relieve stress, to handle personal grief and community violence, and as a coping mechanism for general distress. Understanding how youth think about sexual risk and substance use can inform the design of more effective prevention efforts.

I see its a lot of us going to College!! Thats whats up, bc errbdy thought our generation wasn't about shit...we were only good for making babies $n$ smoking weed $n$ killing each other. Keep it up Everybody, fck what other ppl say-Marie, age 19

Black and Hispanic youth are situated in a society which often places their voices, their experiences and their health at the margins. In scholarship on online communities and public health, this population is systematically under represented or represented in ways that can present youth of color as "problems" or "at-risk" populations. In this study, we examine youth engagement online with three health behaviors; sex, drugs, and alcohol. We consider how youth use social media to have discourse with one another. As evidenced in the leading quote, Black and Hispanic youth are acutely aware of the public health gaze on their health behaviors. In this study, we seek to hear their voices and perspectives on these behaviors vis a vis their digital communications. On networked platforms like Facebook and Twitter, youth of color can and do publicly share their perspectives within their online communities, or what we call digital neighborhoods. In this paper, we examine the ways youth engage with one another in these digital neighborhoods. This is of particular importance as Black and Hispanic youth are more likely to experience negative consequences from sex and drug use (e.g. HIV infection, arrest for drug use) than their white peers who engage in the same behaviors. ${ }^{1-3}$

The digital neighborhood is related to the broader concept of the online community, which has a 20 -year long history of scientific study, beginning with text-based platforms. ${ }^{4}$ From the extensive work of scholars like Lisa Nakamura, Brendesha Tynes, Safiya Umoja Noble and Wendy Chun, we know that youth and people of color experience various layers of discrimination and racism in online communities and that any understanding of digital space must include, if not center POC, LGBTQ individuals and other groups at the margins. ${ }^{5-7} \mathrm{We}$ extended Soukup (2006) work on "digital third spaces", and introduced the digital neighborhood as a concept to distinctly center the experiences of racial and ethnic minorities in their online communities. ${ }^{8}$ Our conceptualization was born from studying the engagement of Black and Hispanic youth with and in networked spaces. The digital neighborhood is a unique conceptual space where normative influences from peer relationships and media converge. Regardless of education or economic status, youth have the greatest uptake of social media of all groups,${ }^{9,10}$ with their underlying goal being to connect with peers ${ }^{9,11}$. Our conceptualization was born from studying the engagement of Black and Hispanic youth with and in networked spaces. Youth communicate attitudes, beliefs, and knowledge; observe normative behavior; and develop and enact their identities. ${ }^{12}$ They also create, seek out, and are exposed to images and text that implicitly and explicitly model behavior and convey normative standards related to sex and substance use. ${ }^{13-16}$ The digital neighborhood interacts with the geographic neighborhood and offline behavior. The question then is how do Black and Hispanic youth use their digital neighborhoods to have open discourse about sex and substances, risk taking and risk avoidance? Additionally, is there any relationship between what is discussed online and real-life behavior?

Adolescence and young adulthood are periods typified by identity development, sexual exploration, and at times, risk-taking. Youth make decisions about participating in risky sexual behavior (e.g. unprotected sex), alcohol use, and other drug use in the context of their social networks, which are often experienced online. While experimentation with sex, alcohol, and substance use is not unique to any 
particular racial, ethnic, or socio-economic group, Black and Hispanic youth (particularly those living in low-income neighborhoods) are disproportionately vulnerable to negative outcomes associated with sexual risk and substance use. For example, in 2011 African-American youth accounted for $15 \%$ of the US population aged 13 to 19 years, yet they represented $67 \%$ of HIV diagnoses in this age demographic. ${ }^{17}$ This burden of disease persists even as Black youth continue to use condoms at significantly higher rates than their white counterparts. ${ }^{1}$ This is in part due to disease density within sexual networks of African Americans rather than individual behavior. ${ }^{18,19}$ Similarly, Black youth experience more negative consequences from alcohol and marijuana use, even though they exhibit similar or lower rates of usage as white youth. ${ }^{3}$

Using a combination of machine learning and manual coding, we examine how minority youth talk about sex, alcohol and other drugs, in their digital neighborhoods ${ }^{15}$; operationalized here as the amalgamation of an individual's various social media platforms where social relationships and media converge. In this study, we investigate youth voices on sex and substance use expressed on social media, focusing on Twitter and Facebook. At the time of study implementation, Facebook and Twitter were among the most popular social media platforms among Black and Hispanic youth with $75 \%$ of Black and $70 \%$ of Hispanic youth, aged $13-17$, reported using Facebook and $45 \%$ of Black and $34 \%$ of Hispanic used Twitter. ${ }^{20}$ While social media and the digital neighborhood remain prominent constructs in the lives of youth, little is known about how youth generally, and Black and Hispanic youth specifically, talk about sexual and substance use behavior online. This study seeks to amplify the voices and perspectives about sex and substance use expressed by youth that are often under explored.

Several studies report that youth use social media to display alcohol use, substance use, and sexual risk behaviors. ${ }^{12,21-24}$ There is also growing evidence that posting about alcohol, and marijuana are related to offline risk behavior. In a recent metaanalysis across 17 studies, social media related alcohol engagement is associated with both alcohol consumption and alcohol related problems, though most of the included studies are cross sectional. ${ }^{25}$ Most of this research focuses on largely white, middle class youth with minimal minority youth representation; yet minority youth are most at risk of negative outcomes from engaging in sexual risk behaviors and substance use. This study provides a much-needed characterization of the use of social media for posting about risky behaviors among Black and Hispanic youth and links their online posting behaviors to their youth risk behavior in real life. In addition, other than public posting, we often do not have access to the messages shared between youth on social media. This study fills that gap by asking what insights we can gain about youth perspectives, experiences, and attitudes related to sex and substances by using social media as lens. How do Black and Hispanic youth use social media specifically to publicly discuss sex and substance use to one another? How does this information differ from what we learn from research approaches using traditional tools (e.g. surveys, interviews)? Finally, we ask how what is discussed online mirrors offline behavior. To answer these questions, we content analyzed youth posts, examining differences in posting behaviors by demographics and reported offline behaviors.

\section{Methods}

Sample Description

The data for this study was taken from a subsample of a larger mixed methods study, with detailed methods previously published. ${ }^{14,15}$ The original study included Black and Hispanic youth $(n=247)$ who completed a behavioral survey at baseline and 12-month follow-up. Participants were self-identified Black and Hispanic(a) adolescents and young adults aged between 13 and 24 years (Mean=18.74, $\mathrm{SD}=3.07$ ). The study city is a small northeastern city in the United States, where approximately $36 \%$ of the population is living below the federal poverty line and the city is ranked second to last in the nation for safety ${ }^{1}$ (Census, 2012). Consent or parental consent and youth assent were obtained for all participants. Participants were compensated $\$ 40$ for completing the assessment and sharing their social media data. Surveys were collected using Medialab v2012 computerized selfassisted interview (CASI) software or online using Qualtrics and took approximately 45 minutes to complete. Survey topics included social media use, sexual behavior, alcohol use, and other drug use.

Youth were recruited using a modified venuebased sampling technique, ${ }^{26}$ by recruiting youth from identified sites and times in the city where youth frequented over the course of several months. These venues included a wide range of community-based organizations and youth support organizations, as well as bus stops and corner stores near schools. The research team recruited youth during times when the 
team previously observed high youth traffic, working with organizational staff when appropriate.

These analyses focus on a subset of youth participants $(n=50)$, who enrolled in the social media arm of the study and shared their previous year of Facebook and Twitter posts. After completing the survey, youth were screened and enrolled in the social media arm. To be included, youth had to use Facebook or Twitter. They then downloaded an app that shared their past social media posts with the research team. Table 1 details demographic differences between those who opted in and those who opted out. There were no significant demographic or behavioral differences between the participants who were included in the analyses and those who were excluded.

\section{Behavioral Surveys}

The surveys were administered at eight community-based organizations and at the University. This diversity of sites allowed youth to participate in the study in their neighborhoods and based on their availability. The majority of youth completed the surveys at their recruitment venues: $33 \%$ were conducted at afterschool programs, $24 \%$ at housing or community centers, $17 \%$ at the university, and the remaining $25 \%$ at agencies supporting youth in transition including GED and vocational training programs or centers supporting homeless youth. The Institutional Review Board at the sponsoring institution approved all study procedures.

Of the 50 participants who shared both their social media data and survey data, males and females were almost equally represented in the sample with women comprising $52 \%$ of the sample. The majority of the participants had sexual intercourse $(66 \%)$ and drank alcohol (62\%). A little less than half of them used drugs (48\%). The majority of the participants used the internet $(83 \%)$ and social media $(70 \%)$ several times a day.

\section{Content Analytic Procedures}

Our approach combined human and natural language processing (NLP) methods in an established data-driven approach that to generate coding categories. ${ }^{27}$ To identify posts in the social media dataset that were related to sex, alcohol, or drugs, the research team developed a dictionary of terms and phrases related to the risk behaviors of interest. The team drew on previously published research and feedback from the youth advisory board to identify terms and phrases in the local lexicon. The NLP process began by extracting Twitter and Facebook posts that contained words and phrases, emoticons, abbreviations, and hashtags related to generally to sex, drugs and alcohol. ${ }^{28}$ We iteratively refined our list of keywords and phrases on a test set of data until the list was finalized for final application to our study dataset. In total, 3,457 posts were extracted from 50 users (259 Twitter posts from 8 users and 3,198 Facebook posts from 45 users; 3 participants provided data for both platforms). The research team developed and applied a qualitative codebook using both inductive and deductive techniques. ${ }^{29}$ Additional codes were added inductively during analysis of the data, with the assistance of a youth advisory board. The final codebook included three risk behavior categories (e.g. sex, drugs, alcohol), with subcategories for each of these behaviors to provide greater insight into the specific meaning of a risk related post. For posts related to sex, codes were developed for "sexual intercourse", "sexual content", "pregnancy", "condoms", "STIs", "HIV”, "nudity" and "LGBTQ". For posted related to drugs, codes were developed for "marijuana" and "anti-drug messaging". For alcohol, a code was developed for "binge drinking". The content analysis was performed by a team of four trained research assistants, comprised of a lead coder and three secondary coders. All team members demonstrated high reliability, with Cohen's kappa greater that 0.80 on all codes.

\section{Measures}

Frequency of internet use and social media use were measured as "How often do you go on the internet," and "How often do you use social media?" 30 Response options were recoded into five categories; never, less than once a week, once or more a week, daily, and several times a day.

The lifetime risk behavior measures were taken from the Youth Risk Behavior Survey. ${ }^{31}$ Lifetime sexual intercourse was measured with, "have you ever had sexual intercourse?". Lifetime marijuana use was measured as, "have you ever, even once, smoked marijuana?". Lifetime alcohol use was measured with the item, "Have you ever, even once, had a drink of any alcoholic beverage, that is, more than a few sips?" Response options included 'yes', 'no' and 'I don't know'. "I don't know" was recoded to 'no.' We also collected self-reported age and gender. For subgroup comparisons, age was recoded into two groups: 13-18 years old and 19-23 years old.

Based on the content analyses, we derived several count variables of the social media data: sex related posts, alcohol related posts, and drug related posts, assessing how many times a participant posted about a given topic (e.g. sex, drugs, alcohol, HIV). For the subgroup analyses, we dichotomized these frequencies into ever or never posting about a topic.

Statistical Analyses 
For both survey and content analytic variables, we include appropriate descriptive statistics (e.g. frequencies and means). Fisher's exact tests, twosample t-tests, and Pearson's correlations were used to test associations between posting and offline behavior and participant demographics. We conducted content analysis of the posts to identify emergent themes, patterns and categories for subsequent analyses. Patterns revealed through the content analysis were then evaluated against the quantitative findings. Pseudonyms are used throughout.

\section{Results}

Table 1 shows demographic information, media use, and posting behavior for the total survey sample $(n=254)$, the social media sample $(n=50)$, and the non-social media sample $(n=204)$. There were no significant differences between participants who provided social media data and those who did not on any of the measured variables.

Posting behavior. The largest number of posts by the participants were about sexual content (Mean=11.28, $\mathrm{SD}=19.44)$, followed by posts about drugs $(\mathrm{Mean}=6.58, \mathrm{SD}=15.46)$ and alcohol $(\mathrm{Mean}=2.62$, $\mathrm{SD}=4.26)$. Sex related posts were most often related to sexual intercourse (Mean=3.44, $\mathrm{SD}=6.19)$ and rarely about condoms (Mean $=0.08, \mathrm{SD}=0.34)$. For drugs, consumption was the most common topic (Mean=6.24, $\mathrm{SD}=14.89$ ) while anti-drug posts were the least frequent $(\mathrm{Mean}=0.34, \mathrm{SD}=0.85)$.

Differences in posting behavior by behavior and demographics. Participants who had consumed alcohol were more likely to post about alcohol on social media $(\mathrm{OR}=4.1911,95 \%$ C.I. $=[1.0715$, $16.8350], \mathrm{N}=50)$. There was a non-significant trend whereby youth who had previously had sex were more likely to post about sex $(\mathrm{OR}=3.9200,95 \%$ C.I. $=[0.8249,19.1571], \mathrm{N}=50)$ and those who had used drugs were more likely to post about drugs $(\mathrm{OR}=2.0446,95 \%$ C.I. $=[0.5127,8.0321], \mathrm{N}=50)$.

Content analytic findings. Several themes emerged from the qualitative analysis of the social media posts. We identified three broad themes related to sex posts: sexual health, gender roles, and trust. Drug and alcohol posts converged around three themes related to substance use generally: substance use modeling; norms and moderation; and stress, grief, and coping. The sample of posts from Twitter was small but had no significant thematic differences than Facebook posts. In this section with describe the themes and provide exemplar posts. Additional examples are shown in Table 3.
Sex Theme 1: Sexual Health. A variety of posts related to sexual health emerged, many pertaining to the importance of HIV and STI testing in particular. Several participants identified lacking health insurance as a common barrier to testing and mentioned various local resources to gain access to testing and treatment. Shakira (pseudonym), a 21 year old woman, highlighted the importance of talking with your partner about testing before sex in multiple posts:

“...Y' Y'll don't know y'all partner history they can tell $u$ anything $n$ its your choice to believe them or encourage them to get checked before dey touch $u$. . . there's a lot of clinics dat test for STDs for ppl wit no insurance. \# take care $y^{\prime}$ all selves cause if $u$ won't ain't nobody else gone to."

"Half of $y$ 'all boyfriends $n$ girlfriends be having no medical insurance how y'all getting checked n cured up !! Somebdy shit turned to aids by now $n y^{\prime}$ all don't even know it. team Medicare B n team NJ horizon I $m$ insured believe dat I can access all my results $n$ medical history online. don't believe me I got prove I know my status. \#Go get checked out \#Nobodys safe"

Youth expressed fear and disgust around the idea of STIs, but few spoke concretely about how STIs or HIV are transmitted. While sexual health issues were not the predominant theme within sex-related posts, some health promoting content was shared within the digital neighborhood, adding some valuable public health knowledge to the discourse. In addition, a large majority of sexual health related posts were from girls and young women.

Sex theme 2: Gender Roles. A recurring topic of discussion was the experience of a double standard applied to young women with regards to sex. Participants noted that young men were able to pursue multiple sexual partners without social ramifications, but when young women did the same or were perceived to behave similarly, they were censured within the digital neighborhood. Norms about gender roles were both reinforced and challenged by the participants. Many posts used terms such as "whores" and "hoes" to describe women who were sexually active. Equally common, however, were posts that challenged this normative belief. Several participants expressed their belief that sexual desire is normal and acceptable for young women, and that labels such as "whore" and "slut" were inappropriate and damaging. Marie, age 19, shared her opinion; " $i$ dont consider a female or male 
a hoe, slut,whore, or watever you want to call them. hell if you like to fuck you just like to fuck lol shared her opinion." These opinions came from both young men and young women. Isaiah, a 16-year old young man noted the judging of women's sexuality, while simultaneously blaming women for their response to social judgement, "It's crazy how girls are judged for having sex and liking sex. Everyone likes sex but yall scared of being called and hoe and shit". Jay, a young man aged 21 expanded the conversation to male sexuality, "Just because I want/like sex doesn't mean I'm a slut", suggesting that men are also judged negatively for sexual behavior. Beyond slut shaming, another theme arose around gender and sex as youth opined that women bear a much larger burden of responsibility for the consequences of sexual activity (e.g. the risk of pregnancy), while men are able to avoid responsibility.

Sex theme 3: Condom Use and Trust. Conversations around safe sex and sexual health often included a focus on trust, or lack of trust, in sexual partnerships. Participants talked about the importance of safe sex in the context of uncertainty around their partners health status and other, current or previous, sexual partnerships. Shakira specifically related condomless sex to partner trust posting; " $N * * * * *$ stay screaming they don't trust bitch. But everytime you hit a bitch Raw, you trusting that bitch!" - female, age 21 (note: asterisks added by researchers)

The practice of 'stealthing', or non-consensual condom removal, was mentioned in a single post that was retweeted from a popular Twitter account. The original tweet was widely shared, with 759 retweets and over 2,000 likes. David, age 20, retweeted to another digital neighbor, "RT@[username]: "Had sex with my FWB and came in her. Told her I used a condom. Next time I saw her she told me her boyfriend got her [pregnant emoji]" While we can't discern whether David is sharing a joke or reference real life behavior, the popularity of the tweet suggests sexual 'stealthing' is being amplified as a potentially acceptable norm within this digital neighborhood. The high number of likes and retweets of the posts only adds to its legitimacy.

\section{Substance Use Theme 1: Stress, Grief, and Coping}

Substance use, specifically alcohol and marijuana use, is discussed as a strategy to relieve stress; to assuage feelings of grief when confronted with personal or community violence; and as a coping mechanism for emotional or psychological distress more generally. Alex, a 20 year old man shared his immediate intention to drink heavily, "Im going to drink until ma soul cant take any more \#gdnt'. Similarly, Petrina, age 24, shared her desire
“I jus wanna drink or 20 !’. Niya, a 21-year old woman, positively associated polysubstance use with relaxation after a long but good day; "I'm finally relaxed from my first day of work tired as hell bout to drink this drink smoke this blunt $n$ then its time to hit those zzzzzzzzz.... had a good day".

In addition to relaxation, substance use postings were also associated with grief about violence and loss. Marie, age 19, lamented the loss of life in her community over the course of the year, and describes drinking rum in conjunction with this reflection: "guesss im in for the night going to drink some rum $\&$ and watch tv \#blessed to make it through another year being so young an seeing so much of my generation lives being taken away. may those RIP who didnt live to see the ending of 2013". Alex, a 20year old man, was affected by personal tragedy and used social media to express his grief over this loss.

"I Swear [name] bro im getting wasted for your cday nobody can tell me nothing be out here tripping Bro $i$ really miss you. Just trying to here your laugh one more time cro im throwing one back with a dutch and a blue cap kno dat croo!" Drinking and smoking marijuana are both a tribute to his lost companion, and an outlet for his own grief.

Marijuana served as a coping mechanism for young people who were experiencing emotional or psychological distress more generally. Several youth mentioned using marijuana when life became overwhelming, or when their thoughts and feelings seemed out of control. Several also noted that marijuana use, although not healthy, was a useful coping mechanism. Liza, age 20 shared; "When everything start kicking in iTake a puff of the dutch too get my mind off it 'I know it ain't good! But it's just Sonething bout it '<3 -_-" . Alex, a 20 year old man echoed a similar sentiment, "I know why I smoke so much my mind be racing... need a different approach".

Substance Use Theme 2: Substance Use Modeling

A few youth used social media as a platform to talk about their substance use, often modeling excessive drinking, marijuana use and sex. In several posts, Shakira connected drinking to romance, friendship, or more explicitly to sex: "Okay I'm qetting wasted $n$ prolly high on new years hopefully I qet to spend it with my boo, ! N my bestie [name]" She also posted, "My boyfriend onnnnn right now he drunk a whole half of pint of henny $n$ on to the next bottle of henny $n$ I ain't even touch my Bacardi he Rey act up at Olive garden omg but we Rey have it tonight getting away from ppl goin to get a room !! We outcheaa toniqht!!!”.

Some participants implied that they were currently drinking or were currently drunk. Niya 
shared "Sippin on tgis bottle wish my peoples stop procastinatin $n$ drink this bottle wit me $u$ kno who $u$ are lol...." Posts like Niya's often included explicit or implicit requests for others to join them in binge drinking. Keem, a 24 year old male, similarly shared "I really shouldt b dis fuked up...o well nd I'm not dun letz get wasted". It is notable that the few participants who posted about using substances were older, typically above the legal drinking age., and likely less closely monitored by parents.

It was an uncommon but notable occurrence for young people to describe and model substance use on social media, including both binge drinking and drinking in combination with sex. Some participants may have purposefully censored this type of posting behavior, knowing that substance use is illegal for most of them. This supports the result from the qualitative analysis that found that older participants tended to post more about drugs and alcohol.

Substance Use Theme 2: Moderation and Control Norms

A substantial portion of the discourse on substance use included talk about moderation in use and maintaining control. In some cases, participants expressed disdain for the social behaviors they observed in their peers who used drugs and alcohol. Marie, a 19-year old women shared, "gettin twerks at every party "turning up"posting half naked ass pictures on social media". Another women, 21 year old Manaya cautioned, "It is not cute to drink and party monday-sunday. Is that all $u$ got going in life ????"

Many youth drew connections between substance use and problems in school and home life. The negative consequences highlighted included wasting money buying drugs and alcohol, substance use interfering with one's ability to manage personal responsibilities, and drugs affecting school work and opportunities for higher education. Shakira explained;

"I really cant get pass when $i$ embarrassed myself when $i$ turned 19th and got so drunk and was acting a dunkie! I wish $i$ could rewind cuz thats not me but $i$ guess that day I had the wild bull in me lol! But nver again will i turn up like dat! Thats $y$ i do not drink heavy becuz i use to love dat party lifee and clubbinq $i$ can say im a change woman thanks to my kids $<3$ They made me become the best mom i could be $<3$ "

Marie boasted about how her digital neighbors were excelling in spite of being negatively stereotyped "I see its a lot of us going to College!! Thats whats up, bc errbdy thought our generation wasn't about shit...we were only good for making babies $n$ smoking weed $n$ killing each other. Keep it up Everybody, fck what other ppl say". While very few participants endorsed abstinence from drugs or alcohol, many highlighted the negative consequences of excessive substance use. Overall, posts that promote moderation and control related to substance use were relatively common; more common than those that modeled substance use.

\section{Discussion}

The digital neighborhood is an online space were youth engage with one another about sex, marijuana, and alcohol. Their posts reflect the discourse that is broadcasted online, whilst simultaneously directed at peers. These posts provide insight how youth think about and navigate sexual risk and various reasons for substance use. Studying social media posts allow us to access to youth in situ, witnessing, if you will, a semi-private conversation amongst networked peers. Though sex, drugs and alcohol account for a small part of their discourse, their messages on those topics offer rich content from voices often at the margins of public health, science and technology studies.

One role of social media for Black and Hispanic youth is to convey and discuss sex and substance use norms, attitudes and beliefs. For the most part, youth did not feel that needed to be engaging in these behaviors to post opinions about them. In terms of sex and drugs, those topics were a discussed by youth who were engaging as well as youth who weren't. The only associative posting we found was related to alcohol, where youth who posted about alcohol, also reporting drinking in real life, a finding is consistent with a recent meta-analysis..$^{25}$ It is possible that the lack of association between online posting and offline sex and drugs use behavior was due to the small sample size.

Youth discuss sexual health, specifically sexually transmitted infections and condom use, as a part of the discussion of their sexual lives. There are also posts that challenged stereotypical gender norms, as well as posts that reinforced them. Girls and youth women are more likely to post about outcomes from sexual risk behavior, specifically HIV/STI and pregnancy. While protection from HIV/STIs and pregnancy requires participation from both sexual partners, it is notable that boys and young men were less likely to post about sexual health online, though they post about sexual intercourse more frequently.

With regard to substance-related content, substance use served a number of functions for youth. Youth detail the use of marijuana and alcohol in response to stress, grief and as coping mechanisms. When the dominate response to adolescents and young adult substance use is criminalization, the use 
of substances for coping in response to grief, stress and tragedy deserve further examination. Older youth are more likely to post about alcohol, perhaps as youth are legally able to drink, they feel more comfortable posting about consumption.

This paper opened with the quote from a participant we call Marie. Marie boasted about how her digital neighbors and peers were excelling in spite of being negatively stereotyped as pregnant, violent and drug using. In this single post, Marie illuminates the power of social media and digital neighborhoods in the lives of youth like her. The platforms gave her access to the accomplishments of her peers whom she may or may not have interacted with in her daily offline life. She amplified the collective successes and encouraged others to continue striving academically. She directly addressed the negative characterization of her generation and countered using the evidence drawn from the social media postings about college acceptances across her digital neighborhood. Social media gave Marie a public platform to respond to negative and racist stereotyping of Black and Hispanic youth. As scientists, we owe it to youth using social media to voice their responses to us, to their environment, and to their situations, to listen with the same intensity we do to other sources of data.

From the systems science perspective, it is important to continue to interrogate how social media platforms can amplify the voices of those at the margins. In order to do this, we must consider how those same voices are often rendered invisible and ignored. With the exception of a cadre of scholars (e.g. Nakamura, Tynes, Noble, Patton, Chun). Black and Hispanic digital neighborhoods, voices and experiences are largely invisible in studies of health, new media and technology. This invisibility can conceal the ongoing effects of racism and segregation within the neighborhood. When we fail to center these voices, we also miss the opportunity to witness how youth strategically navigate risk and health in

\section{References}

1. Hallfors DD, Iritani BJ, Miller WC, Bauer DJ. Sexual and Drug Behavior Patterns and HIV/STD Racial Disparities: The Need for New Directions. American Journal of Public Health. 2007;97(1):125-132.

2. Bowleg L, Neilands TB, Tabb LP, Burkholder GJ, Malebranche DJ, Tschann JM. Neighborhood context and Black heterosexual men's sexual HIV risk behaviors. AIDS Behav. 2014;18(11):22072218.

3. Boyer CB, Shafer M-A, Wibbelsman CJ, Seeberg D, Teitle E, Lovell N. Associations of their online and offline social spaces. More broadly, scholars should interrogate how the digital neighborhood serves to increase or reduce health disparities. For example, does the discourse around health topics on social media further burden marginalized communities by amplifying misinformation or excluding useful information and resources?

Limitations. The most significant limitation is the study sample size. These analyses lack the statistical power to test associations and largely focus on trends and provides context to the qualitative analyses. However, the richness of the qualitative analysis helps to offset this weakness. We feel confident that the findings are likely similar across the larger study sample of 247 youth, as there were no differences in the portion of the sample that shared their social media and those who did not. The findings from this study are drawn from Black and Hispanic youth living in a high poverty urban area and should not be generalized beyond this type of community of youth.

\section{Conclusion}

This study provides a unique opportunity to hear youth voices related to health and risk behaviors that are common across youth development but uniquely impact minority youth. Social media provides an excellent way to gain a window into youth perspectives and the ways they broadcast and communicate about their lives, beliefs and behaviors to their digital neighbors. While there are many prevention efforts focused on using social media to "reach" communities, these findings suggest that a better understanding and integration of youth in the actual development of prevention efforts might be more effective in supporting risk reduction behavior. We suggest further work seeks ways to leverage the perspectives of Black and Hispanic youth by considering their voices, experiences, and patterns of language and communication with peers in their digital neighborhoods.

sociodemographic, psychosocial, and behavioral factors with sexual risk and sexually transmitted diseases in teen clinic patients. Journal of Adolescent Health. 2000;27(2):102-111.

4. Malinen S. Understanding user participation in online communities: A systematic literature review of empirical studies. Computers in Human Behavior. 2015;46:228-238.

5. Tynes BM, Giang MT, Williams DR, Thompson GN. Online racial discrimination and psychological adjustment among adolescents. The Journal of adolescent health : official publication of the Society for Adolescent Medicine. 2008;43(6):565-569. 
6. Nakamura L. Cybertypes: Race, ethnicity, and identity on the Internet. Routledge; 2013.

7. Noble SU. Algorithms of Oppression: How search engines reinforce racism. NYU Press; 2018.

8. Soukup C. Computer-mediated communication as a virtual third place: Building Oldenburg's great good places on the world wide web. New Media \& Society. 2006;8(3):421-440.

9. Madden M, Lenhart A, Cortesi S, et al. Teens, Social Media, and Privacy. Pew Internet \& American Life Project 2013; http://www.pewinternet.org/2013/05/21/teenssocial-media-and-privacy/. Accessed October 17, 2014.

10. Chou W-yS, Hunt YM, Beckjord EB, Mosser RP, Hesse BW. Social Media Use in the United States: Implications for Health Communication. Journal of Medical Internet Research. 2009;11(4).

11. Livingstone $\mathrm{S}$. Taking risky opportunities in youthful content creation: teenagers' use of social networking sites for intimacy, privacy and selfexpression. New Media \& Society. 2008;10(3):393-411.

12. Boyd D. It's Complicated: The Social Lives of Networked Teens. New Haven, CT, USA: Yale University Press; 2014.

13. Stoddard SA, Bauermeister JA, Gordon-Messer D, Johns M, Zimmerman MA. Permissive norms and young adults' alcohol and marijuana use: the role of online communities. $J$ Stud Alcohol Drugs. 2012;73(6):968-975.

14. Stevens R, Gilliard-Matthews S, Dunaev J, Todhunter-Reid A, Brawner B, Stewart J. Social media use and sexual risk reduction behavior among minority youth: Seeking safe sex information. Nursing research. 2017;66(5):368377.

15. Stevens R, Gilliard-Matthews S, Dunaev J, Woods MK, Brawner BM. The digital hood: Social media use among youth in disadvantaged neighborhoods. New Media \& Society. 2017;19(6):950-967.

16. Moreno M, Briner L, Williams A, Walker L, Christakis D. Real use or "real cool": adolescents speak out about displayed alcohol references on social networking websites. Journal of adolescent health. 2009;45(4):420-422.

17. Centers for Disease Control and Prevention. Rates of diagnoses of HIV infection among adults and adolescents, by area of residence, 2011--United States and 6 dependent areas. HIV surveilance report. 2013;23:1-84.

18. Adimora AA, Schoenbach VJ, Doherty IA. HIV and African Americans in the southern United States: sexual networks and social context. Sex Transm Dis. 2006;33(7 Suppl):S39-45.
19. Adimora AA, Schoenbach VJ, Floris-Moore MA. Ending the Epidemic of Heterosexual HIV Transmission Among African Americans. American Journal of Preventive Medicine. 2009;37(5):468-471.

20. Lenhart A. Teen, Social Media and Technology Overview. 2015.

21. boyd d. Why Youth $\bullet$ Social Network Sites: The Role of Networked Publics in Teenage Social Life. The John D and Catherine T MacArthur Foundation Series on Digital Media and Learning. 2007;-:119-142.

22. Moreno M, Christakis D, Egan K, Brockman L, Becker T. Associations between displayed alcohol references on Facebook and problem drinking among college students. Arch Pediatr Adolesc Med. 2012;166(2):157-163.

23. Yonker LM, Zan S, Scirica CV, Jethwani K, Kinane TB. "Friending" teens: systematic review of social media in adolescent and young adult health care. J Med Internet Res. 2015;17(1):e4.

24. Cookingham LM, Ryan GL. The impact of social media on the sexual and social wellness of adolescents. J Pediatr Adolesc Gynecol. 2015;28(1):2-5.

25. Curtis BL, Lookatch SJ, Ramo DE, McKay JR, Feinn RS, Kranzler HR. Meta-Analysis of the Association of Alcohol-Related Social Media Use with Alcohol Consumption and AlcoholRelated Problems in Adolescents and Young Adults. Alcohol Clin Exp Res. 2018;42(6):978986.

26. Muhib FB, Lin LS, Stueve A, et al. A venuebased method for sampling hard-to-reach populations. Public Health Rep. 2001;116:216222.

27. Riloff. E. An Empirical Study of Automated Dictionary Construction for Information Extraction in Three Domains. . Artificial Intelligence. 1996;85:101-134.

28. H. Andrew Schwartz JE MLK, Lukasz Dziurzynski, Stephanie Ramones, M. Agrawal, A. Shah, A., M. Kosinski, D. Stillwell, Martin Seligman, and Lyle Ungar. . 2013.;8(9). Personality, Gender, and Age in the Language of Social Media: The Open-Vocabulary Approach. . PLOS ONE 2013;8(9).

29. LaRossa R. Grounded Theory Methods and Qualitative Family Research. Journal of Marriage and Family. 2005;67(4):837-857.

30. Madden M, Lenhart A, Duggan M, Cortesi S, Gasser U. Teens and Technology 2013. Pew Research Center; 2013/03/13/ 2013.

31. CDC. Youth Risk Behavior Surveillance System (YRBSS). 2016; https://www.cdc.gov/healthyyouth/data/yrbs/inde x.htm. 
Table 1: Demographics \& Number of Posts in 3 categories by: Total Sample (n=50); Full Wave, Social Media, Those Excluded from Social Media

\begin{tabular}{|c|c|c|c|}
\hline Variable & $\begin{array}{l}\text { Social Media } \\
\text { No }(\%) \text { Or Mean (SE) }\end{array}$ & $\begin{array}{l}\text { Non-Social Media } \\
\text { No }(\%) \text { Or Mean (SE) }\end{array}$ & $\begin{array}{l}\text { Total } \\
\text { No }(\%) \text { Or Mean (SE) }\end{array}$ \\
\hline Total & $\mathrm{N}=50$ & $\mathrm{~N}=204$ & $\mathrm{~N}=254$ \\
\hline Age (years) & $18.74(3.07)$ & $19.14(3.25)$ & $19.03(3.20)$ \\
\hline Female & $25 / 48(52 \%)$ & $115 / 199(58 \%)$ & $140 / 247(57 \%)$ \\
\hline Male & $23 / 48(48 \%)$ & $84 / 199(42 \%)$ & $107 / 247(43 \%)$ \\
\hline Internet Use & & & \\
\hline$<$ Once a week & $6 / 48(13 \%)$ & $17 / 101(17 \%)$ & $23 / 149(15 \%)$ \\
\hline About once a day & $2 / 48(4 \%)$ & $14 / 101(14 \%)$ & $16 / 149(11 \%)$ \\
\hline Several times a day & $40 / 48(83 \%)$ & $70 / 101(69 \%)$ & $110 / 149(74 \%)$ \\
\hline Social Media Use & & & \\
\hline$<$ Once a week & $6 / 47(13 \%)$ & $23 / 100(23 \%)$ & $29 / 147(20 \%)$ \\
\hline Once a day & $8 / 47(17 \%)$ & $10 / 100(10 \%)$ & $18 / 147(12 \%)$ \\
\hline Several times a day & $33 / 47(70 \%)$ & $67 / 100(67 \%)$ & $100 / 147(68 \%)$ \\
\hline Total Sexual Posts & $11.28(19.44)$ & --- & $11.28(19.44)$ \\
\hline Total Alcohol Posts & $2.62(4.26)$ & --- & $2.62(4.26)$ \\
\hline Total Drug Posts & $6.58(15.46)$ & --- & $6.58(15.46)$ \\
\hline Ever Had Sex & $33 / 50(66 \%)$ & $93 / 128(73 \%)$ & $126 / 178(71 \%)$ \\
\hline Ever Drank Alcohol & $31 / 50(62 \%)$ & $90 / 129(70 \%)$ & $121 / 179(68 \%)$ \\
\hline Ever Had Drugs & $24 / 50(48 \%)$ & $71 / 128(55 \%)$ & $95 / 178(53 \%)$ \\
\hline
\end{tabular}

Table note: NSF in any of test groups. 
Table 2: Cross Tabulations of posting type (Sex, Alcohol, Drug) by offline behavior (ever had sex, ever drank, ever used marijuana; $\mathrm{N}=50$ ).

\begin{tabular}{|c|c|c|c|c|c|c|c|c|c|}
\hline & \multicolumn{3}{|c|}{ Ever Had Sex } & \multicolumn{3}{|c|}{ Ever Drank Alcohol } & \multicolumn{3}{|c|}{ Ever Smoke MJ } \\
\hline & Yes & No & Total & Yes & No & Total & Yes & No & Total \\
\hline $\begin{array}{l}\text { Ever Post } \\
\text { Sex }\end{array}$ & $\begin{array}{l}28 \\
(56 \%)\end{array}$ & $\begin{array}{l}10 \\
(20 \%)\end{array}$ & $\begin{array}{l}38 \\
(76 \%)\end{array}$ & & & & & & \\
\hline $\begin{array}{l}\text { Ever Post } \\
\text { Alcohol }\end{array}$ & & & & $\begin{array}{l}22 \\
(44 \%)^{*}\end{array}$ & $\begin{array}{l}7 \\
(14 \%)^{*}\end{array}$ & $29(58 \%)$ & & & \\
\hline $\begin{array}{l}\text { Ever Post } \\
\text { MJ }\end{array}$ & & & & & & & $\begin{array}{l}15 \\
30 \%\end{array}$ & $\begin{array}{l}9 \\
18 \%\end{array}$ & $\begin{array}{l}24 \\
48 \%\end{array}$ \\
\hline
\end{tabular}

Table note: $* \mathrm{P}>.05$, based on Fisher's Exact Test $(\mathrm{p}=0.0221)$ 
Table 3: Content Analytic Themes and Exemplar Posts

\begin{tabular}{|c|c|}
\hline Themes & Exemplar Posts \\
\hline \multirow[t]{3}{*}{ Sexual Health } & $\begin{array}{l}\text { I feel bad for ppl . ppl who doesn't have Medicaid or insurance don't get checked . y'all wall in . } \\
\text { when y'all get dat HIV u gon wish u checked up n cared more bout ya health Y'all don't know } \\
\text { y'all partner history they can tell u anything n its your choice to believe them or encourage } \\
\text { them to get checked before dey touch u ... there's a lot of clinics dat test for STDs for ppl wit } \\
\text { no insurance. In\# take care y'all selves cause if u won't ain't nobody else gone to . }\end{array}$ \\
\hline & $\begin{array}{l}\text { Jus left the OBGYN I swear that doctor wanted me on the low lol she gone do the exam and } \\
\text { smile at me ctfuuu I'm in my head like lady I would bust ya ass in this doctors office you better } \\
\text { stop that lmao :') that's where half of y'all females need to go cause y'all be steady talking shit } \\
\text { about the next girl but you ain't get ya pussy checked since } 2010 \text { stop it __- }\end{array}$ \\
\hline & $\begin{array}{l}\text { all these young boys think its cute to get a girl to ice them but when the get freezer burnt ion } \\
\text { wanna here nothing. you can still get a std from getting head }\end{array}$ \\
\hline \multirow[t]{6}{*}{ Gender Roles } & $\begin{array}{l}\text { S/O too all the males who get around fuckn, and wanting to fuck every female ( "all they } \\
\text { bitches" )and end up catching something but got the heart too call females hoes an whores } \\
\text { :) \n\#BOOM \#yall do a great job tryna cover yaself up }\end{array}$ \\
\hline & $\begin{array}{l}\text { Niggas is wild they be all in a girl bussin her ass raw knowing the consiquences of they actions } \\
\text { but still doin him ! Then Wen she began to swell } n \text { throw up they want no parts } n \text { they duckinq } \\
\text { ! Like boy grow the Fuck up and man up ! Bms Niggas need to be US for a month so they can } \\
\text { see what we go threw and maybe they wouldn't dear! }\end{array}$ \\
\hline & $\begin{array}{l}\text { I cant stand lil Girls thats Whores! Like } \mathrm{u} \text { aint even a teenager yet } ! \& \& \mathrm{u} \text { fuckinq like dat ! } \\
\text { This world is sour \&\& aint shit sweet anymoree! \&\& } \mathrm{N}^{* * * * *} \text { too With they lil ass Dicks } \\
\text { Burning ppl KNowin they got that shit ! In\# JS =Ramdom thought }\end{array}$ \\
\hline & $\begin{array}{l}\text { t's crazy how girls are judged for having sex and liking sex. Everyone likes sex but yall scared } \\
\text { of being called and hoe and shit }\end{array}$ \\
\hline & Just because I want/like sex doesn't mean I'm a slut. \\
\hline & $\begin{array}{l}\text { i dont consider a female or male a hoe,slut,whore, or watever you want to call them . hell if } \\
\text { you like to fuck you just like to fuck lol }\end{array}$ \\
\hline \multirow[t]{2}{*}{ Trust } & $\begin{array}{l}\mathrm{N}^{* * * * * *} \text { (sic) stay screaming they don't trust bitches. But everytime you hit a bitch Raw, you } \\
\text { trusting that btch! }\end{array}$ \\
\hline & $\begin{array}{l}\text { I'm so tired of these dizzy ass no good ass lil Dick } \mathrm{n}^{* * * * *} ! \text { Fuckin everything walking } \mathrm{n} \text { not } \\
\text { even caring bout them selfs! Likee boys talk bout they std free but haven't even seen a clinic } \\
\text { yett Man yall } \mathrm{N}^{* * * * *} \text { need papers now yall can't be trusted ! Fareal ! In\# Talkingg bout all } \\
\mathrm{N}^{* * * * *} \text { no one inperticular! But man yu } \mathrm{N}^{* * * * *} \text { wild Fareal ! In\#Lms if u agree }\end{array}$ \\
\hline \multirow[t]{5}{*}{ Stress/Grief/Coping } & I jus wanna drink or $20 !$ \\
\hline & $\begin{array}{l}\text { I'm finally relaxed from my first day of work tired as hell bout to drink this drink smoke this } \\
\text { blunt } n \text { then its time to hit those zzzzzzzzz..... had a good day }\end{array}$ \\
\hline & Im going to drink until ma soul cant take any moreln\#gdnt \\
\hline & $\begin{array}{l}\text { I Swear [name] bro im getting wasted for your cday nobody can tell me nothing be out here } \\
\text { tripping Bro i really miss you. Just trying to here your laugh one more time cro \nim throwing } \\
\text { one back with a dutch and a blue cap kno dat croo! }\end{array}$ \\
\hline & $\begin{array}{l}\text { When everything start kicking in iTake a puff of the dutch too get my mind off it ' I know it } \\
\text { ain't good ! But it's just Sonething bout it ' }<3 \text {-_- }\end{array}$ \\
\hline \multirow[t]{4}{*}{$\begin{array}{l}\text { Substance Use } \\
\text { Modeling }\end{array}$} & $\begin{array}{l}\text { My boyfriend onnnnn right now he drunk a whole half of pint of henny } \mathrm{n} \text { on to the next bottle } \\
\text { of henny } \mathrm{n} \text { I ain't even touch my Bacardi he Rey act up at Olive garden omg but we Rey have it } \\
\text { tonight getting away from ppl goin to get a room !! We outcheaa toniqht!!! }\end{array}$ \\
\hline & $\begin{array}{l}\text { Sippin on tgis bottle wish my peoples stop procastinatin } \mathrm{n} \text { drink this bottle wit me } \mathrm{u} \text { kno who } \mathrm{u} \\
\text { are lol.... }\end{array}$ \\
\hline & $\begin{array}{l}\text { Okay I'm qettinq wasted } \mathrm{n} \text { prolly high on new years hopefully I qet to spend it with my boo, ! } \\
\mathrm{N} \text { my bestie [name] }\end{array}$ \\
\hline & if I can buy weed everyday my money is long! !! \\
\hline
\end{tabular}




\begin{tabular}{|c|c|}
\hline $\begin{array}{l}\text { Moderation/Control } \\
\text { Norms }\end{array}$ & $\begin{array}{l}\text { I hate qettin pissy drunk! I was at the partty likee askin my self please turn tf dwn !! Just woke } \\
\text { up im so tired I can feel it still } n \text { my system. Good thing no hang ovaa came upon me! }\end{array}$ \\
\hline & $\begin{array}{l}\text { While all yall fools spending all that money on clothes,shoes,jewelry, weed and liquor! Just } \\
\text { think for one min how much money you would have if you save that money instead of trying to } \\
\text { impress these fe(males) that really don't care about you only your money that your spending on } \\
\text { stupid stuff and then you turn around a complain your in the hood! Smh } \backslash n \text { \#bulidingmyempire }\end{array}$ \\
\hline & gettin twerks at every party "turning up"posting half naked ass pictures on social media \\
\hline & It is not cute to drink and party monday-sunday. Is that all u got going in life ???? \\
\hline & $\begin{array}{l}\text { I hate when ppl take not even } 4 \text { sips of liquor and be sayinq they feelinq it \& fallinq all over } \\
\text { like stfu sit the hell dwn } n \text { have a seat ! u can tell if a person is really drunk or not ! \# ppl make } \\
\text { fools outta they self }\end{array}$ \\
\hline
\end{tabular}

